Revista Iberoamericana. Vol. LXVII, Núms. 194-195, Enero-Junio 2001, 31-54

\title{
EXILIO Y TRÁNSITOS ENTRE LA NORZAGARAY Y CHRISTOPHER STREET: ACERCAMIENTOS A UNA POÉTICA DEL DESEO HOMOSEXUAL EN MANUEL RAMOS OTERO
}

\author{
POR \\ JoSSIANNA ARRoyo \\ Universidad de Michigan
}

A Guillermo y Paco, viajeros en el amor

\begin{abstract}
El miedo al miedo ya no existe, todavía me inquietan los aviones de plata que a las 6 tajean la cara del cielo, pero entiéndelo, ni yo me voy ni tú vendrás, ha sido el pacto de nuestro silencio, todo fue previsto por los muertos que siempre han habitado esta isla. Hace tiempo que pensaba escribirte que solamente los habitantes de esta isla tienen la sabiduría de la soledad. — - Manuel Ramos Otero. "En la orilla amarilla de la muerte hay algo".
\end{abstract}

El intento de acercarse a una poética del deseo homosexual en Manuel Ramos Otero parte siempre desde un discurso del desencuentro y la espera. El amante espera en un espacio indeterminado, la llegada de un amado, que tarda en aparecer o nunca llega. Estos espacios pueden recrear una atmósfera distinta: la casa que se derrumba y cierra sus puertas, el bar solitario en una noche de lluvia o el espacio de la calle que se extiende en coordenadas diversas. La isla de soledad, tanto desde el lirismo de sus cuentos como desde su poesía, puede ser Puerto Rico como lugar imaginado de ensueño y distorsión carnavalesca o Manhattan con sus encuentros fortuitos y sus pesadillas del tiempo. ${ }^{1}$ Por consiguiente, puede afirmarse que "la escritura transeúnte" de Manuel Ramos Otero — como la ha identificado agudamente Juan Gelpí (137) — remite a un discurso amoroso del tránsito y lo transitorio. El tránsito, metáfora estructuradora de El libro de la muerte (1985), equivaldría al desplazamiento continuo de un espacio individual, la figura móvil del inmigrante, que

\footnotetext{
${ }^{1}$ Aunque quisiera acercarme a la poesía particularmente, parece casi imposible no aludir a la cuentística. Según Juan Gelpí en "La escritura transeúnte de Manuel Ramos Otero” resulta díficil establecer una separación de géneros en este autor, y por lo tanto este tránsito puede aplicarse al cruce de géneros tan frecuente en su escritura: "Si el canon es una forma de establecer territorios y trazar fronteras, la obra de Manuel Ramos Otero se aparta de él, pues arranca precisamente de una proliferación de lo transeúnte y móvil, tanto en la materia narrada como en el modo narrativo” (137). En la reseña que acompaña la edición de El libro de la muerte, Gelpí añade: “Sus 'cuentos' descartan la geometría férrea del cuento tradicional y se construyen a partir de la imagen, del lirismo y la ambigüedad”. Por lo tanto, se puede calificar su poesía como un género narrativo, lírico y alegórico constituyéndose así como "género híbrido".
} 
transita desde Puerto Rico hasta Nueva York. ${ }^{2}$ Y por consiguiente, los pequeños reconocimientos o muertes que adquiere ese sujeto en conjunción a ese espacio citadino ante el regreso o la partida. Desde ese punto de vista, la calle adquiere un valor alegórico: la Norzagaray dibuja el imaginario del San Juan que se ve como trazo desde un avión, y los amantes que se lleva la nostalgia, mientras que Christopher Street reproduce un signo nuevo, del encuentro fortuito, del nuevo amante, del encuentro diario con el cuerpo, con el disfrute y con la muerte. Por consiguiente, se reproduce un texto poético de ausencias y presencias, de "lo fijo" como ilusión versus lo transitorio. ${ }^{3}$ Es, desde este último contacto, que se produce lo transitorio como equiparador de estas dos coordenadas y el imaginario del deseo se impone frente a estos dos puntos de partida y desencuentros.

Estos desencuentros reformulan el imaginario de lo urbano en Invitación al polvo (1991), en donde el espacio se hace mucho más íntimo y la nostalgia reproduce un discurso del cortejo amoroso a solas, el soliloquio con la muerte y con la poesía. Aquí el cuerpo como agente deseante remite a la ficción y procura traducirse a sí mismo (Vega 24). Por lo tanto, a través de los dos poemarios se propondrá una redefinición de un imaginario que está en un «afuera»(i.e. el cuerpo del amante, las dos Islas, la calle), en lucha diaria en un espacio político, para luego volcarse en un gesto íntimo a la "epifanía” de un texto deseante. ${ }^{4}$ Una voz poética que se reproduce en sí y para sí misma, y que traduce las “entregas” simbólicas de los amantes.

En este ensayo propongo una lectura de la poesía de Manuel Ramos Otero, desde sus dos poemarios El libro de la muerte (1985) e Invitación al polvo (1991), como la de un discurso del deseo erótico que se desplaza y evade las propuestas de un espacio fijo, y por consiguiente, se sitúa en un “afuera” geográfico y espacial. El “yo poético” internaliza el espacio de la calle en un plano subjetivo, para dialogar abiertamente con temas como el amor, la muerte o la nostalgia. La inclusión de estos temas, también incorpora una reflexión del deseo homosexual como representante individual del cuerpo del sujeto colonial y la inmigración. ${ }^{5}$ Desde este punto de partida, quiero relacionar el sujeto colonial-homosexual

\footnotetext{
2 Estos continuos desplazamientos del sujeto colonial migrante son leídos por Homi K. Bhabha como creadores de lo que llama "wandering people" ("DissemiNation: Time, Narrative and the Margins of the Modern Nation").

${ }^{3}$ Para Jacques Lacan, el orden simbólico, el estado en que se produce el lenguaje, se articula desde el sujeto deseante, el cual reproduce un discurso de lo "transitorio". Ya que este deseo se organiza como lenguaje y va creando estructuras metonímicas (de ausencia y presencia) que crean a su vez el deseo por el Otro o el "Deseo del Deseo": "Este deseo de hacer reconocer su deseo, en el que se verifica literalmente que el deseo del hombre se enajena en el deseo del Otro, estructura en efecto las pulsiones descubiertas en el análisis, según todas las vicisitudes de las sustituciones lógicas, en su fuente, su dirección, su objeto[...]" (Citado de J. Lacan Ecrits, en el ensayo de Néstor A. Braunstein. "Las pulsiones y la muerte (Collage)" 11-80).

${ }^{4}$ Arnaldo Cruz Malavé en su ensayo "Para virar al macho: la autobiografía como subversión en la cuentística de Ramos Otero” sitúa estas “epifanías”, en comparación de Ramos Otero con Cortázar, como instantes de lo maravilloso. Estos pueden relacionarse con un encuentro sexual con el amante o un instante de reconocimiento cercano a la muerte o la desesperación. Ver el cuento: "En espera de las ratas azules". Cuentos de buena tinta (9-12).

${ }^{5}$ En ese sentido, el cuerpo del homosexual "negocia" sexual y políticamente sus espacios. Ver el ensayo de Jossianna Arroyo "Manuel Ramos Otero: las narrativas del cuerpo más allá de Insularismo"
} 
y sus políticas, leyendo así los usos de una conciencia política de la homosexualidad como poder agencial.

Es así como, en Christopher Street como espacio político, y desde un movimiento "gay" proveniente de Estados Unidos, se replantea el deseo homosexual como una negociación del cuerpo y el lenguaje con las economías del capital. De ese modo, el “deseo gay” siempre se asocia con un cuerpo cruzado por las economías de mercado:

Sexuality is inextricably tied to capitalism's requirements for reproduced labour of different values, the bouyant consumerism of the metropolitan economies and, as with all capitalist social relations, sexuality's material construction is effected not only directed through the market, but also mediated through the state's formal machineries and practices of citizenship, and in all these arenas sexuality is, albeit attenuated a channel of class relations. (Evans 36)

El cuerpo del homosexual aparece, entonces, como el lugar en donde coinciden los signos del deseo y de la sociedad de consumo. En ese sentido, el deseo se establece a partir de una "homografía” en donde el homosexual se hace "visible" e "invisible” y "circula" en un orden referencial de signos (Edelman). Los protagonistas en la poesía de Ramos Otero, reproducen estos signos cambiantes en su propio cuerpo. Es así como en el Libro de la muerte el cuerpo del homosexual no sólo protagoniza la diáspora, sino también, frecuenta el "leather bar", consume bienes (o cuerpos) y "crucea” en Christopher Street. ${ }^{6}$ Por consiguiente, este discurso sobre y desde el cuerpo reformula nuevas categorías y alianzas "hibrídas" a un nivel económico, cultural y sexual.7 Para Rubén Ríos, este discurso, centrado mayormente en el cuerpo que "circula" hace que la narrativa de Ramos Otero se sitúe en la ciudad de Nueva York, para plantearse otro tipo de ciudadanía-negociada, "fuera” de la gran familia puertorriqueña como construcción "homogénea” nacional (101).

En ese sentido, New York, la polis del "consumo" actúa como cuerpo transformativo en la reelaboración del imaginario de la Isla, el de la “otra orilla”, el San Juan “desde la

y su descripción del cuento "Vida ejemplar del esclavo y el señor” (Cuentos de buena tinta 179-84), en donde el narrador utiliza la relación sicológica y política del amo y el esclavo en una relación sexual sadomasoquista para ejemplificar la relación del colonizador-colonizado.

${ }^{6}$ La palabra "cruceo" alude al acto de "cruising" o de caminar en algún espacio público en búsqueda de una pareja sexual. Según Evans, en su ensayo Sexual Citizenship. The Material Construction of Sexualities, la adquisición de los bienes del mercado, por ejemplo en la cultura "leather" el pantalón de cuero o las botas que van en juego, remiten a una economía de mercado propia de la subcultura gay, que sugiere que actividades como el "cruceo" se conviertan en una exhibición del cuerpo y de la vestimenta.

${ }^{7}$ Cuando hago alusión del término "hibridez cultural” utilizo la definición de Néstor García Canclini en su texto Culturas híbridas. Estrategias para entrar y salir de la modernidad. Por otro lado, la lectura que hago de las alianzas culturales parte del ensayo de Georges Yúdice y Juan Flores "Living Borders/ Buscando América: Languages of Latino Self Formation”. En Ramos Otero estas alianzas se dan en un espacio urbano y metaforizan desde el discurso de los amantes, nuevas construcciones de identidad en el emigrado. Desde este punto de vista, el texto poético que tiene por tema fundamental el amor, se instituye como un texto que propone alianzas entre los emigrantes. En este caso el texto poético pasa por un proceso de traducción lingüística. 
Norzagaray”. Aquí, “ la Isla” se inscribe de un modo distinto, representando un discurso que escribe las políticas del cuerpo desde el carnaval, lo circense y la simulación. Es aquí donde la máscara travesti realiza sus "traducciones” de referentes culturales y se apropia, como ya veré en detalle más adelante, de “otro” canon homosexual y de lo oriental. ${ }^{8}$ Lo oriental, lejos de ser una construcción fija, aparece a partir de la creación y la traducción como motivo interno - externo, como otredad dentro de la otredad misma, maquillando un rostro y desvistiendo un cuerpo. En conclusión, Libro de la muerte recupera, desde el espacio de lo urbano, un discurso de concientización agencial — política del homosexual y escribe en la máscara su imaginario “circular” del cuerpo del deseo.

Por otro lado, a pesar de ser un poemario donde el espacio de la calle sigue siendo un referente, en Invitación al polvo el cortejo amoroso deja a un lado el reto que la máscara poética impone como apropiación y desafío en el Libro de la muerte. Así la primera parte del texto, titulada "Del polvo enamorado", recupera una poética del cortejo amoroso centrada en la figura de José, el amante habanero. El poema "La víspera del polvo" individualiza desde el SIDA las metáforas contradictorias del cuerpo nacional para pasar finalmente a un discurso que se "quita la máscara” y se ubica en el juego poético como recital-homenaje ante la muerte. ${ }^{9}$

Al proponer una poética del deseo homosexual frente al espacio urbano, es necesario definir cómo se localiza este cuerpo con respecto a las instituciones del llamado "poder" colonial. En estas negociaciones de poder — como señala Michel Foucault, en The History of Sexuality - el estado crea las políticas que "inventan” y disciplinan desde un discurso religioso y moral las preferencias sexuales (14). En los poemarios de Ramos Otero, el homosexual como sujeto colonial traduce las contradicciones y las negociaciones de la identidad puertorriqueña. De ahí que las políticas estatales estén relacionadas con lo sexual. Por un lado, el homosexual negocia su cuerpo con un discurso del capitalismo avanzado, la economía de mercado y la adquisición de bienes, la cual crea —durante los años 70— la visión de una cultura hedonística, dada al "pursuit of pleasure” (Evans 45). ${ }^{10}$ También y a pesar de que es una minoría sexual: "which is constantly under review through the competing and ambigous pressures of both amoral market and fetishized state” se concientiza

\footnotetext{
${ }^{8}$ La presencia temática de lo oriental parte de un diálogo de la poética de Ramos Otero con la estética modernista de Julián del Casal y Rubén Darío, específicamente, en sus usos de la máscara poética como eje representativo del cruce de identidades políticas y subjetivas. Las miradas al "otro" oriental como archivo y espacio mimético se centran en este diálogo entre lo "propio" y el "afuera" que forma al sujeto colonial. Exploro estos cruces en detalle en mi definición de la máscara oriental (ver nota 15). Ver el ensayo de Edward W. Said. Orientalism. (New York: Random House, 1979).

${ }^{9}$ Aunque, tanto en la poesía, como en la ficción se propone el espacio del cuerpo homosexual individualizado como reformulación de lo nacional, este análisis corresponde a mi trabajo anterior (citado anteriormente). Por otro lado, quisiera situarme fuera de una lectura que intente redefinir lo nacional, para proveer un análisis donde se lean desde escenas particulares, estos espacios de la calle en relación a un discurso del deseo que aunque forma una entidad de sujeto, no la conforma y recrea a su vez un discurso de "frontera" individual.

${ }^{10}$ Este "salirse del closet” como acto público, según señala Evans, ocurrió en Christopher Street a causa de los motines en contra de la policía en el bar Stonewall en el Greenwich Village del 28 al 29 de junio de 1969 (66).
} 
políticamente y “sale del closet” en la metrópoli. Sin embargo, se enfrenta a las contradicciones de las dos sociedades, específicamente de la construcción de la masculinidad puertorriqueña en la que tradicionalmente el hombre "pasivo" es quien se deja penetrar, mientras que el "bugarrón” pasa a ser el que posee un grado de masculinidad superior (Almaguer; Alonso y Korec; Ramírez). ${ }^{11}$

Por el contrario, la construcción de un discurso del deseo homosexual en la poética de Ramos Otero juega con estas construcciones culturales — "activo" o "pasivo" - y con las diversas subversiones que se van realizando desde el espacio sexual y socio-político. La máscara poética destaca, en ese sentido, los productos de una hibridez cultural y revelan las posibles alianzas entre las minorías o entre distintos grupos culturales. Estas alianzas homoeróticas, vistas como un lenguaje o código propio, alegorizan desde otro punto de vista el "crossover" que leen Flores y Yúdice: "Latino experience in the US has been a continual crossover, not only across geopolitical borders but across all kinds of cultural and political boundaries" (215). Este "crossover" de alianzas discursivas se lee desde un espacio individual en donde el amante, que desea el cuerpo presente o ausente del amado, traduce un lenguaje propio que parte de su condición de sujeto colonial-homosexual. La "hibridez" de estos códigos lingüísticos produce entonces un discurso del deseo que se va creando a partir de "otros” discursos: el "kitsch" literario y el "performance”. Ambos, como veré más adelante, reformulan un espacio discursivo complejo en donde el deseo adquiere la ilusión de categoría ya escrita (el kitsch) o por hacerse en su condición repetitiva (el performance) (Butler). El homosexual o "la loca” aparece, entonces, como un tipo de significante híbrido y del lenguaje, lo que Oscar Montero define como "the signifying queen”, que "as a tutelary deity, leads the way in search for an autochthonous queer reading of Latin American identities and cultures[...]" (162). Es así como el lenguaje del deseo, también construye una alianza con la parodia, el juego y lo lúdico, especialmente en Invitación al polvo en donde se hace un pacto con el deseo y con la muerte.

Sin embargo, desde la lectura interior de la ciudad y sus coordenadas — la Norzagaray o Christopher Street - se abre un espacio en donde la "cultura urbana” produce un cruce significativo, lo que García Canclini ve como "las fuerzas dispersas de la modernidad" (264). Es ahí en donde caerían, efectivamente, estas poéticas de deseo frente al imaginario estatal. Mi lectura de la poesía de Ramos Otero busca enmarcar los relatos de la presencia de una cultura urbana, en donde se reproducen imágenes “impuras” y cruces entre lo público y lo privado (en este caso lo social y lo sexual) (García Canclini 264). Es, desde este punto

\footnotetext{
${ }^{11}$ Aunque como han señalado Tomás Almaguer, Ana M. Alonso y María Teresa Koreck, las prácticas sexuales en las comunidades chicanas y mexicanas se conducen a partir de códigos de "actividad" o "pasividad”, en el caso de Puerto Rico, la realidad no es muy distinta. Esta es la conclusión a la que llega Rafael L. Ramírez en su ensayo Dime capitán: Reflexiones sobre la masculinidad. Considero que esta descripción de la homosexualidad desde un comportamiento "pasivo" o "activo" a pesar de que responde a las visiones tradicionales del machismo en la cultura puertorriqueña siempre son debatibles y no responden a la realidad de muchos homosexuales en la sociedad puertorriqueña para quienes ser "activo" o "pasivo" no representa un "control" sobre el cuerpo del otro, y se relaciona más con el placer sexual. En un ensayo reciente Richard Parker discute contradicciones similares en el manejo de estas categorías en los homosexuales brasileños. Ver Beneath the Equator: Cultures of Desire, Male Homosexuality and Emerging Gay Communities in Brazil.
} 
de vista, que este discurso puede calificarse como neo-colonial. ${ }^{12}$ Mayra Santos, en su ensayo "La venganza de los circuitos cerrados", propone que la cultura urbana puertorriqueña está ante "una cuestión virtual mutante” en donde los espacios urbanos se confunden:

La calle está dura y la ciudad es un negocio. Ya los lugares urbanos no son comunidades de habitantes, la vida verdadera ocurre en otra parte (las urbanizaciones)[...] De noche se va al punto a capear, al cine, a alquilar un trasvesti, a la disco, al bar. Los espacios públicos abiertos se vuelven más inhabitables más si se anda sin dinero [...] En nuestras cabezas los medios de comunicación han instalado imágenes en donde aparece cadáver tras cadáver, balacera tras balacera, charcos de sangre, botellas rotas, pura agresión. (3) ${ }^{13}$

Aunque se privilegia lo urbano, como el lugar de los cruces de una "post” nación, en esta poesía se produce un texto subjetivo, donde las articulaciones del deseo aparecen como significantes y lo literario sigue siendo el punto de partida. Frente al poder aberrante de la imagen se sobrepone el "kitsch" literario y el performance, siempre en conjunción con el texto de los dos amantes. El cuerpo deseante que se desplaza apropiándose de las tácticas del colonizador en un proceso de "mimicry" o travestismo subversivo va creando nuevas posiciones de sujeto en su espacio social (Bhabha 88). Es así como, se elabora un texto deseante donde el cruceo es metáfora del tránsito y lo transitorio y el acto sexual reformula nuevas coordenadas de posesión que parten del deseo insatisfecho. La ciudad que se camina, como propone De Certeau, impone su retórica, la cual se une con una retórica del

\footnotetext{
${ }^{12}$ Es, desde este punto de vista, que se puede localizar un discurso "posible" sobre lo posmoderno en Puerto Rico. Este discurso urbano ha dado entrada a nuevas poéticas que he llamado neo-coloniales (o pos-coloniales) y en las que se puede situar a Ramos Otero. Utilizo el término neo-colonial para describir, en el caso particular de Puerto Rico, un cambio fundamental en las relaciones culturales y económicas con los Estados Unidos. A pesar de que continúa siendo una colonia tradicional, Puerto Rico participa de los discursos culturales creados por el "nuevo orden" económico capitalista y transnacional. Como propone Patricia Seed en su ensayo "More Colonial and Postcolonial Discourses”, ya no puede trazarse una línea clara que separe el "primer” y "tercer” mundo en cuanto a producción cultural se refiere. Propone que: "Cultural forms like the film production of the Kayapo (an indigenous Amazonian people) or Puerto Rican and Dominican theatre in New York can be neither explained nor understood by such categories. Resistance and accommodation gave us good guys and bad guys, black hats and white ones” (150). Estas expresiones del contexto neocolonial puertorriqueño, en donde sitúo a Ramos Otero, buscan criticar o romper con los mitos político-culturales que fueron institucionalizados por la Generación del Treinta como la gran familia puertorriqueña o la "esencia" del puertorriqueño. Aunque estos mitos formaron parte de una corriente de nacionalismo cultural y forjaron un Logos particular que correspondía a una coyuntura histórica específica, prefiguran la formulación de un discurso nacional coherente. Por otro lado, estas nuevas expresiones revelan "otro" discurso mucho más complejo en donde la problematización de un discurso sobre la identidad, incluye otras categorías como la de género y preferencia sexual, raza y el cuerpo individual como locus negociador y agente político. Ver Frances Negrón-Muntaner, Ramón Grosfoguel y Chloé S. Georas "Beyond Nationalist and Colonialist Discourses: The Jaiba Politics of the Puerto Rican EthnoNation”.

${ }^{13}$ Este aspecto que no estudiaré aquí si aparece en varios cuentos de Ramos Otero así como en varios poemas, utilizando el texto "massmediático" como voz parodiada.
} 
deseo (152). La metáfora del escritor exilado, del “artista transeúnte”, se impone entonces para construir el imaginario poético:

\begin{abstract}
El "escritor" ha permanecido en silencio tomando un trago de Southern Comfort, por donde suda a gota larga cada tramo de su sol; mira las palabras ordenadas en secuencia verosímil para el papel (y para ustedes, que siempre han visto y presentido la barrera de un mar sin haberse visto reflejados en el espejo del exilio). (Ramos Otero, Página en blanco, "La otra isla de Puerto Rico" 22)
\end{abstract}

Esta “secuencia verosímil” parte desde un discurso del deseo homosexual al crear, no sólo la máscara del "escritor" con la que se encuentra el texto a veces, sino un juego de cruceos lingüísticos, muertes simbólicas, “performances” celebratorios y desencuentros nostálgicos.

\title{
II. TRAVESTISMO, CRUCEO Y LA MÁSCARA ORIENTAL
}

No. El otro no existe. Uno lo va creando a sueños y a palabras, a manos y pisadas, sometiéndolo a la lenta costumbre del amor. Entonces uno se exila en el amor como en las ciudades. Todo es tan viejo como el sol. Pero la ciudad y el exilio son más viejos que la luna y la noche. La zona del exilio es el mismo territorio de la soledad.

—Manuel Ramos Otero. "El cuento de la mujer del mar".

¿Cómo articular un discurso del deseo que evoque este tránsito físico y subjetivo junto a un continuo desplazamiento, si el discurso del amor precisa de una historia que lo fije? ${ }^{14}$ Las diversas historias poéticas representadas en El libro de la muerte construyen este desplazamiento por medio de un recurso: la máscara poética. Esta máscara poética se construye como ilusión travestida y juego de identidades (i.e. lo masculino, lo femenino, lo oriental) que produce desde su articulación varias instancias. La primera recoge la diferenciación de género sexual como una máscara más. Para Judith Butler estas construcciones de género remiten a un espacio cultural y producen una discontinuidad con respecto a lo sexual. Por lo tanto: "Assuming for the body the stability of binary sex, it does not follow that the construction of 'men' will accrue exclusively to the bodies of males or that 'women' will interpret only female bodies” (6). Partiendo, entonces, desde una subversión de las construcciones culturales en base a género y sexualidad y su problematización, la máscara poética asume diversas "situaciones de género", y las subvierte . La voz poética utiliza el deseo homosexual y las construcciones sociales sobre este deseo - lo femenino, lo masculino-machista, lo oriental-“decadente”, o "lo promiscuo"para elaborar un discurso de tránsito físico y subjetivo. Este tránsito, como ya mencioné anteriormente, alude a un espacio socio-político, situacional y transgrede reglas físicas.

La máscara travesti remite a un espacio alegórico de codificación linguístico-cultural desde donde se problematizan estos mismos códigos de representación. Por ejemplo, la voz poética de “Como todas las mujeres de nuestra raza” se presenta como Penélope esperando por Ulises, y se transforma en Tsugichumo, el oriental vestido de geisha en el poema "Esta

${ }^{14}$ Este es el planteamiento de Roland Barthes en su texto Fragmentos de un discurso amoroso. 
es la segunda parte del Ulysses”. Por lo tanto, esta máscara travesti, como afirma Severo Sarduy, puede verse como un intento de crear "otro" espacio social, otra elaboración artística, un discurso problematizado y abierto (48). Sin embargo, esta máscara incluye, desde sus cambios sucesivos, un "performance" teatral y es, desde este punto de vista, que se incorpora el motivo oriental. ${ }^{15}$ En El libro de la muerte, Tsugichumo y Nechodoma son representantes de un discurso alegórico relacionado con el amor y la muerte. En mi lectura de varios poemas desde estas variaciones de la máscara, veo en el "performance" lúdico los procesos de "reconocimiento" de un espacio imaginario (la calle, la ciudad) y de su transformación. Estas transformaciones, como veré en detalle más adelante, problematizan un discurso sobre el deseo por el otro, el cual aparece corporizado en algunas instancias o como espera nostálgica en otras, para reproducir finalmente un texto poético en donde las categorías espacio temporales se reformulan y el deseo por el otro reelabora "otras" subjetividades en el sujeto poético.

En el primer poema, titulado “De pie a cabeza estaba”, es en el que aparece “encarnado" y textualizado el cuerpo del deseo. El encuentro con el cuerpo del deseo se da como instante fugaz de mirada en la noche, el “cruceo” nocturno que se representa como discurso de poder y creación:

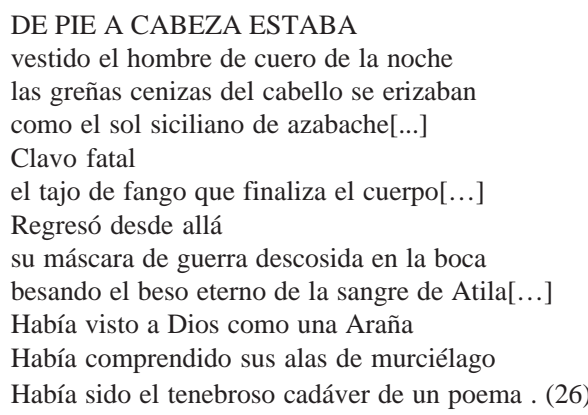

El "hombre de cuero" se encarna, entonces, como el "objeto del deseo" representado a su vez como inmigrante: “como el sol siciliano de azabache”, con máscara de Atila que

\footnotetext{
${ }^{15}$ El uso de lo oriental como motivo literario aparece como uno de tantos códigos representativos del que se apropia Ramos Otero. Este incluye lecturas sobre filosofía oriental, hindú, etc, que como en los modernistas hispanoamericanos Casal, José A. Silva y Darío, y más tarde en Borges, construyen un discurso metafísico sobre el individuo y su realidad. Su incorporación puede sugerir varias instancias. En primer lugar se recupera, de forma paródica, lo oriental como lo "otro" decadente y se relaciona directamente con las construcciones del homosexual propias del siglo xix en el Modernismo hispanoamericano, el Simbolismo francés (el exotismo de la Salomé de Oscar Wilde por ejemplo). También recupera el uso de la alegoría del "performance" del teatro chino y japonés, en particular las obras del teatro Nö japonés, originario del siglo xiII en donde los hombres hacían todos los papeles incluyendo la máscara femenina. Ver ensayo de Edward W. Said citado anteriormente. Sobre el Nö ver el ensayo de Arthur Waley. The Nö Plays of Japan y sobre Oscar Wilde y la literatura hispanoamericana, el ensayo de Sylvia Molloy titulado,"The Politics of Posing”.
} 
regresa de la muerte. Este “objeto del deseo” representado como fetiche y máscara produce, sin embargo, un espacio de agencialidad político-sexual. El espacio de la calle se asume entonces como lugar estratégico en donde se expresan los juegos sexuales y el “cruceo". Por lo tanto, en el ritual del "cruceo" y en el deseo sexual se incorpora un lenguaje de poder (Foucault, History of Sexuality 225). Por otro lado, la inversión de los versos de Luis Palés Matos de "El llamado": "Me llaman desde allá/ A mi lado descansa mi amor sobre la hierba" (Díaz Quiñones 70) revelan la inscripción de una voz masculina (i.e. intelectual/colonizada) ante la muerte recuperando su memoria corporal y por medio de ésta una trascendencia. Aunque la voz poética en “De pie a cabeza estaba”, articula un lenguaje del deseo donde el cuerpo del hombre de cuero es objeto de placer, no se da una trascendencia. El único espacio posible de redención está en ese encuentro con "el clavo fatal/ el tajo de fango que finaliza el cuerpo”. Por consiguiente, la penetración constituye el espacio en donde se puede crear una ilusión de "tránsito" entre la vida y la muerte y una "toma de conciencia” a través del cuerpo. Esta se da entonces al asumir el cuerpo del otro como fetiche y objeto, metaforizando así las negociaciones entre el cuerpo del colonizador y el colonizado. Sin embargo, la petite morte del encuentro sexual posibilita el enfrentamiento con la nada cerrada sobre sí misma en un juego cíclico de pequeñas muertes productoras del “tenebroso cadáver de un poema”. Es así como este yo-deseo produce un espacio discursivo a partir del ritual sexual y de poder que subvierte y negocia el poder agencial a través del “objeto de placer”, que es el hombre de cuero. El cuerpo como fetiche, disfrazado y enmascarado, es el que hace posible el encuentro sexual y va construyendo a su vez a partir de la Araña suspendida los tejidos del “cadáver-cuerpo" que es el poema. El encuentro del cuerpo deseante con el objeto de placer es la metáfora alegórica para la creación de un poder negociador y agencial de la creación poética. Al "crucear", por lo tanto, se articula un texto propio, de conciencia corporal del sujeto colonial, en donde se penetran los cuerpos para producir un texto creador. En conclusión y desde el cuerpo como discurso del poder, se representa la muerte simbólica del sujeto para construir un “otro”, que en este caso sería el poema.

En el segundo poema titulado: “Como todas las mujeres de nuestra raza”, la voz poética utiliza una máscara femenina para hablar de la "patria” como espacio deforme-carnavalesco y del exilio como máscara transculturadora y discurso de la espera:

COMO TODAS LAS MUJERES DE NUESTRA RAZA

al salir del mar y de la noche he sido madre

de mi propio sacrificio:

he parido[...]

el feto secreto de un oráculo deforme[...]

Le hubiera dado un tajo al vientre preñado de mi madre

por haberme bajado de aquel tren en que nos fuimos

He cambiado ciudades como el que cambia islas[...]

He sido Penélope esperanza y no lo entiendo

Creyendo que de nuevo el hombre nuevo invadiría

las pezuñas calientes de mis piernas

Otravez

No es carnaval pero es espejo[...]

El utilero ha puesto un flamboyán en esta esquina[...] 
En los bares de barrio se comenta:

el cojo de la Norzagaray, los Rosarios de Cruz, las Luces de Bengala en la Perla, los títeres achicharrando a Cristo en su altar de gladiolas y azucenas, el lucero punzó sobre mi abuela Ustedes ya comprenden...

la máscara arrugada de Maba no se despega. (19-20)

En “Como todas las mujeres de nuestra raza...”, la apropiación de una voz poética femenina que es la "madre mítica de la nación”, alude al oráculo deforme de la historia del exilio y de la colonización. Asimismo, el matricidio se presenta como un intento de abolir este "parto" en el que se da a luz un sujeto migrante, que está condenado a la espera. Por otro lado, la imagen de Penélope esperando por Ulises alegoriza el deseo insatisfecho y la imagen especular de la Isla transformada en carnaval. Se recupera, entonces, la Norzagaray como sinécdoque de la Isla y el espacio se construye desde la parafernalia teatral. El rostro del exilio pasa a ser una "máscara de Maba que no se despega” y que produce el espacio de circo como acronía temporal y sucesiva, como espacio transculturado, cíclico y temporal. Por lo tanto, en este poema la representación de la voz poética como madre mítica sitúa y caracteriza los dos espacios y el tránsito entre ellos: el del exilio y las “ciudades islas” y el de la calle Norzagaray que se cierra sobre el cuerpo de la abuela.

En "Estoy a un año exacto de mi primera muerte", la voz poética espera por un amado que no regresa. Y aunque su rostro posee "la máscara himalaya de la espera” es también desde el deseo que se construye un imaginario espacial:

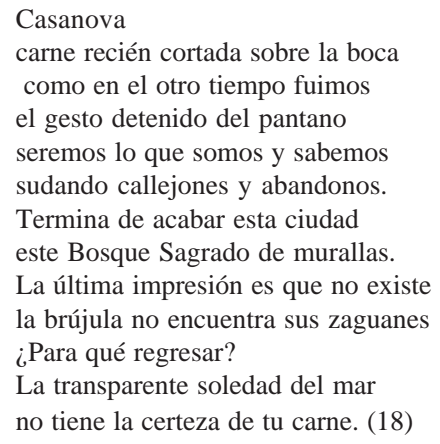

En este poema, la espera se convierte en resignación, mientras que el cuerpo del amante se sitúa en otro espacio fuera del imaginario nostálgico de la Norzagaray. Aunque el deseo sigue siendo el constructo principal, el tiempo se propone aquí como una "máscara himalaya" de resignación frente a la espera en donde "la brújula no encuentra sus zaguanes". En ese sentido, la temporalidad del cuerpo y del encuentro con el amante se determinan a través del tiempo de la ciudad que "no tiene la certeza de tu carne”. 
Por el contrario, el tono que prevalece en el poema "Esta es la segunda parte del Ulysses”, refleja la muerte de Tsugichumo, ${ }^{16}$ otredad y máscara japonesa:

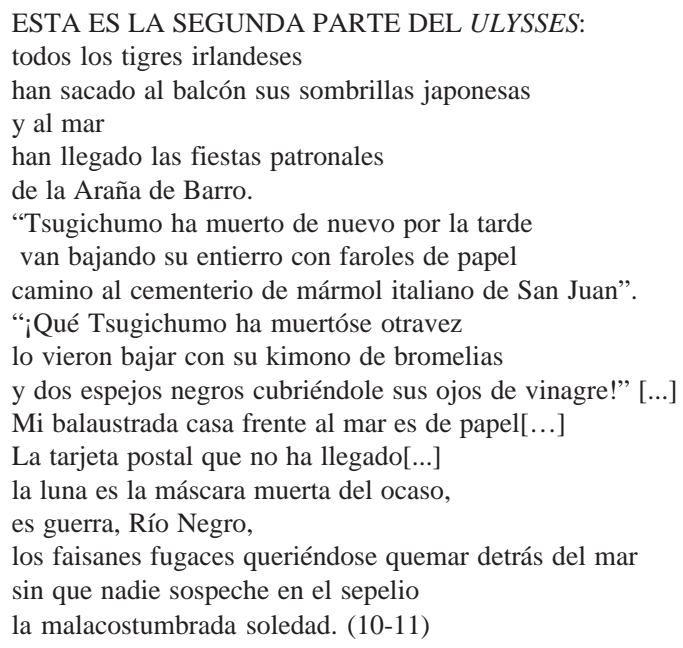

Este poema se revela intencionalmente como "la segunda parte del Ulysses" aludiendo a su construcción de monólogo interior del texto de Joyce que, también en este caso, alude a lo irlandés como otredad colonizada y a Tsugichumo como máscara oriental y travesti. Por consiguiente, el poema puede leerse como un intento por problematizar la máscara del sujeto colonial y "traducir" referentes culturales para producir un texto "híbrido" pero autorreferencial. Por lo tanto, la segunda parte del Ulysses abole su narratividad, se queda con la expresión poética, mas sigue siendo un texto de búsqueda, reconocimientos y esperas. Tsugichumo, la máscara oriental, proyecta la soledad del amante esperando una "tarjeta postal que no ha llegado”. Esta soledad enmascarada se viste con su kimono de bromelias para observar desde “su casa frente al mar”, la procesión de su entierro. Este entierro de una otredad oriental y colonizada, alude a la muerte de una doble identidad. Por un lado, la de la espera, travestida en Tsugichumo y por otro lado, la del sujeto colonial. La muerte simbólica de estas dos identidades, la de la máscara oriental y la del sujeto colonial, revelan un cambio fundamental y problematizan este discurso del deseo en donde el amante, que ya se encuentra en un "afuera", se transforma.

En los dos últimos poemas “Dejénme estar de nuevo en las palabras” y “Aberración de ceniceros sucios aquí”, el amante se desvanece y el imaginario espacial se construye por medio de varias posiciones de sujeto:

${ }^{16}$ Esta otredad oriental, resulta como en la mayor parte de la obra de Manuel Ramos Otero autobiográfica y referencial. Ramos Otero como "performer” de su poesía hizo, durante la década de los '70 en Puerto Rico, lecturas tipo “happenings” de su poesía vestido como geisha oriental. También solía caminar las calles de San Juan vestido con un kimono y con sombrillas de papel de arroz. 


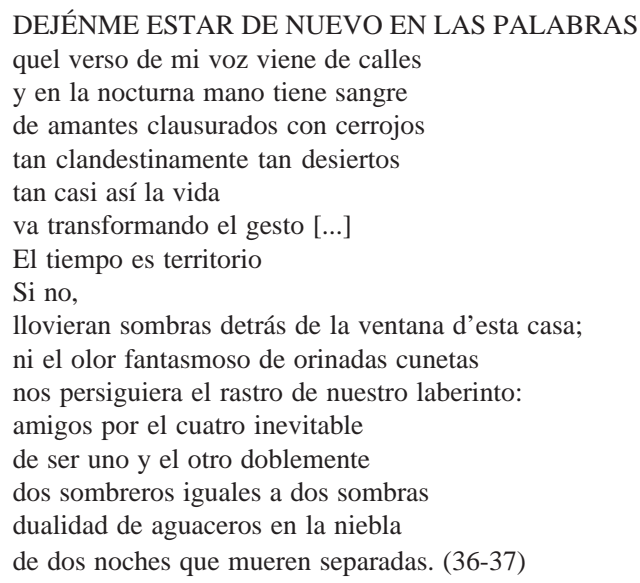

En este poema "el verso viene de calles" y va construyendo otro espacio que sustituye al de los amantes que ya no se esperan. La imagen de la casa cuya ventana se encuentra llena de sombras, remite a las cuatro esquinas, al espacio cerrado del cuerpo: "amigos por el cuatro inevitable” y a las sombras del uno y el otro. Por consiguiente, las sombras que llueven detrás de la ventana son representativas de las transformaciones subjetivas de la voz poética. Entonces, el discurso del deseo se transforma y produce otras reformulaciones espaciales. En primer lugar, los amantes se clausuran y abandonan tanto como la voz poética el espacio de la calle. De este modo, el tránsito asume un carácter rememorativo y de reconocimiento de una otredad interior que se asume desde una casa en ruinas, alegoría del imaginario nacional. Por otro lado, el cuerpo del deseo, el objeto del placer se desvanece: el "hombre de cuero" de la noche como encuentro sexual fugaz y categoría agencial/ política se convierte en sombra y asume un carácter temporal. El tiempo subjetivo pasa a ser, entonces, la categoría que define la continuidad del deseo y su representación del espacio, mientras que la identidad del sujeto se divide y se desplaza desde un espacio en ruinas, la casa, hasta un "afuera” en "sombras” como significante múltiple.

Esta continuidad temporal del deseo se propone en el último poema que analizaré titulado, “Aberración de ceniceros sucios aquí”, donde la calle se representa como totalidad y el cuerpo aparece como escritura en sí mismo:

ABERRACIÓN DE CENICEROS SUCIOS AQUI

el hombre es de polvo por el sol

no hay otro masallá que todo es isla

pero se sueñan calles y el poeta es

de polvo por la luna.

Hambre de muelles pero se van los barcos.

No hay otro masallá que todo es mar.

El único remedio para la muerte.

Pero todos se van. 


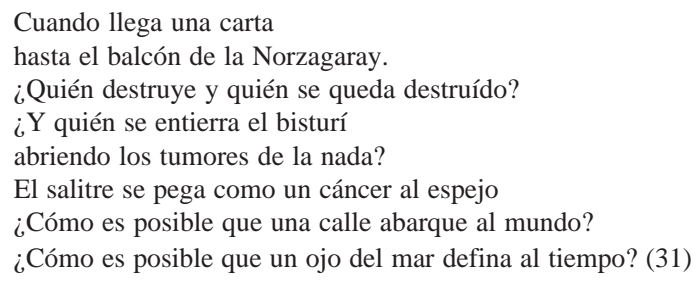

En este poema, el deseo se internaliza como soledad y ausencia. Asimismo, el único instante del poema en el que puede aludirse al cuerpo de un posible amante se obvia: "El único remedio para la muerte/ Pero todos se van”. La imagen del balcón y la casa aparece como espacio que aloja a este cuerpo que alcanza una conciencia de sí mismo pero reformula su pregunta retórica a un "otro” posible: “¿Y quién se entierra el bisturí/ abriendo los tumores de la nada?”. ${ }^{17}$ Por lo tanto, a partir de esta pregunta retórica se crean otros accesos subjetivos frente al espacio que se añora. En primer lugar, el imaginario de la calle pasa a ser un universo que se sueña y el deseo un lenguaje que ya no se articula por medio de ese amante que se espera sino a través de las “otredades” posibles del sujeto poético. Es así como el "ojo de mar que define al tiempo" se cierra en una doble sucesión de historias: la del sueño y la de lo material como “aberración de ceniceros sucios”. Si no hay “otro másallá” ya "que todo es Isla” en el aquí y el ahora, tanto el sujeto poético como sus otros imaginarios, inclusive, el del amor y el amado, están condenados a la circularidad de su propia temporalidad, al encierro del mar y a la duplicidad del espejo.

Por consiguiente, en El libro de la muerte aunque el deseo por el amante y la presencia del exilio produce una poética corporal que actúa como un imaginario especular de nostalgia por el espacio, ésta va reformulándose. Los usos de la máscara como persona poética en calidad de "performer" ubican el texto en un tránsito poético-espacial. Este flujo poético produce varios encuentros y desencuentros, esperas y nostalgias por el amante ausente. Aunque el encuentro furtivo del instante fugaz del "cruceo" produce un instante creativo originario, y de "toma de conciencia” político/agencial, el cuerpo como objeto de placer va desapareciendo por medio de las máscaras (i.e. Penélope, Meba, Tsugichumo, el salitre). En conclusión, el deseo por el otro se reproduce como estrategia poética para asumir una lectura del cuerpo-espacio como lenguaje mismo, mientras que la identidad del sujeto colonial se asume desde la multiplicidad del sujeto poético.

Es, desde este punto de vista, que quisiera acercarme a las poéticas del deseo de Invitación al polvo en donde la máscara poética se reformula y se produce un discurso más íntimo y metapoético. Aquí el hablante poético parte del cortejo amoroso para situarse en

\footnotetext{
${ }^{17}$ Esta cita se refiere a la transformación del cuerpo por medio de la heroína. La heroína en la escritura de Ramos Otero debe ser vista como un planteamiento alterno de este dicurso sobre el deseo y el cuerpo. La penetración del cuerpo por una aguja revela la creación de una conciencia o subjetividad alterna que abole la presencia de ese otro corporal. El cuerpo se abre entonces frente a sus propias limitaciones creando así un lenguaje escritura de sí mismo. Ver un planteamiento similar en Néstor Perlongher y sus "poéticas del éxtasis" en su ensayo titulado "Poesía y éxtasis." Prosa plebeya. Ensayos 1980-1992.
} 
un espacio medio entre la calle y la casa, el exilado y el exilio, el colonizador y el colonizado, el deseo y el poema. Este texto metapoético, aunque no abandona la referencia a un espacio, en este caso el caribeño y el latinoamericano, produce un discurso más abierto que problematiza la construcción de una subjetividad colonizada hacia "otro" espacio: el del exilio perpetuo y el viaje creador.

III. LAS METÁFORAS DEL DESEO: POÉTICAS DEL CORTEJO AMOROSO Y ENFERMEDAD

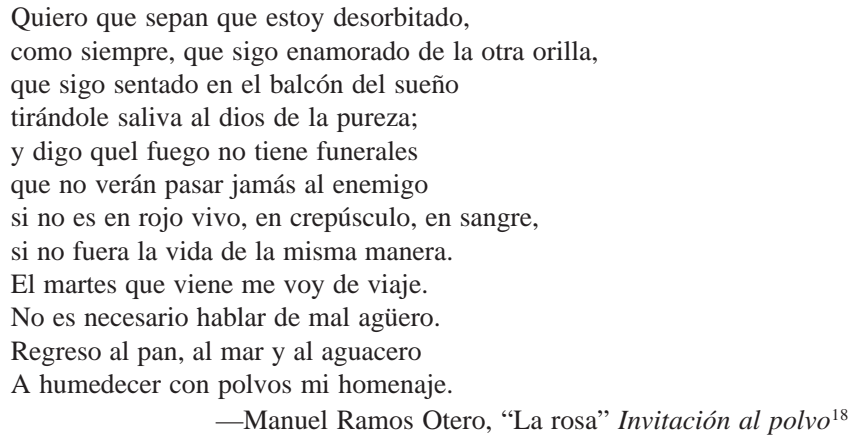

En el poema “La rosa”, la metáfora del viaje remite a lo frágil de la vida y la resignación frente a ese exilio perpetuo que es el de la muerte. Mas, sin embargo, el yo poético continúa reafirmando la imposiblidad de sentirse “completo" en el deseo y el amor. Es, desde este discurso amoroso, que se reformulan las poéticas del deseo y la enfermedad de Invitación al polvo, un texto que como afirma José Luis Vega, remite a dos significados de la palabra “polvo", el biblíco "Polvo eres y al polvo volverás” y el amoroso de "echar un polvo”, relacionado con el encuentro sexual (Vega 19). El poeta parte, entonces, de los versos de Quevedo: "Su cuerpo dejará, no su cuidado;/ Serán ceniza, más tendrán sentido;/ polvo serán, más polvo enamorado”. También el poeta vuelve sobre la materialidad de sus textos, como literatura, para reescribir la poesía de cortejo amoroso del Siglo de Oro español y el Barroco colonial americano, los poemas de Luis Cernuda y Lola Rodríguez de Tió, y situar la relación entre el poeta y José, su amante cubano. Por consiguiente, en la primera sección titulada "De polvo enamorado" la metáfora de los dos amantes remite a un discurso latino e iberoamericano. Este espacio permite a su vez el movimiento entre varios registros, que van desde el bolero y la música popular hasta el cortejo amoroso y creativo de las poéticas

\footnotetext{
${ }^{18}$ Este texto salió publicado en 1991, luego de un año de la muerte del poeta en una actividad de recordación, organizada por los familiares y amigos escritores del poeta en la galería del Museo de Arte e Historia en el Viejo San Juan. La actividad titulada “Homenaje al Poeta”-“Chú” ( 1948- 1990), contenía una colección de fotografías tomadas en su mayor parte por Vanessa Droz y objetos pertenecientes al poeta: su silla, su escritorio, su máquina de escribir. El mismo día se llevó a cabo un homenaje en el City College de Nueva York en conjunto con la Administración y el profesorado de ambas universidades. Efraín Barradas hizo referencia a estos actos de "canonización oficial”, resaltando la condición de hereje y marginal que tuvo siempre en las letras puertorriqueñas.
} 
culteranas del Siglo de Oro y el Barroco (San Juan de la Cruz, Quevedo, Góngora, Sor Juana Inés de la Cruz, Lope de Vega).

Este motivo literario reproduce un discurso doble que aunque hace referencia al ser amado como objeto de deseo, lo sitúa en un plano metafísico y en un "afuera” textual. También, y desde este “afuera” del cuerpo del amado, se centra sobre sí mismo, creando así, un sujeto poético heterogéneo. Esta identidad múltiple de sujeto poético sustituye la "máscara del sujeto colonial” en un juego de metáforas mucho más fluido y consciente del proceso de creación. Crear, por consiguiente, es problematizar las múltiples identidades de un sujeto poético, y jugar con su "hibridez” intertextual y córporea. Por lo tanto, aquí se presenta un discurso que juega con las posibilidades corporales del texto, su juego erótico ante el lector, y produce la creación desde la heterogeneidad como "foreplay" seductor.

En la segunda sección titulada “La víspera del polvo” se recoge la metáfora del SIDA y el contagio, lo que individualiza las metáforas del cuerpo nacional y produce un texto que actúa como "réquiem” volcado hacia la poesía. ${ }^{19}$ En el último poema, titulado con los versos de Julia de Burgos "La nada de nuestros nunca cuerpos”, se escribe un texto elegíaco en donde se recupera lo femenino como esencia de la creación poética. En los cuatro poemas que analizaré, pertenecientes a la primera y la segunda sección, se ve la fragmentación del cuerpo del amado que remite a otro discurso sobre el deseo. En este discurso, la poesía de tono lúdico del cortejo amoroso se une con las poéticas del cuerpo enfermo para crear nuevas relaciones transitorias en el espacio que se añora y el sujeto poético. Ante la inminencia de la muerte física, la metáfora del viaje se abre como el cuerpo a una propuesta más abarcadora, universal y metapoética. Mientras el deseo concibe el cuerpo del amante como fragmento, el texto poético reelabora su perpetuidad para realizar, ante la muerte, un réquiem celebratorio de sí mismo y de su seducción. De ahí, que el cuerpo se diluya en cenizas y polvo y el poema como lenguaje deseante articule la escritura como tránsito perpetuo.

Es, desde este cuerpo fragmentado, que leo en el poema 10 la erotización del poema por sí mismo, a partir de la fragmentación del amado y la transferencia final a la escritura poética. Aunque el cuerpo del deseo se reproduce de un modo fragmentario, éste se retoma para producir el poema que asume un cuerpo por sí mismo:

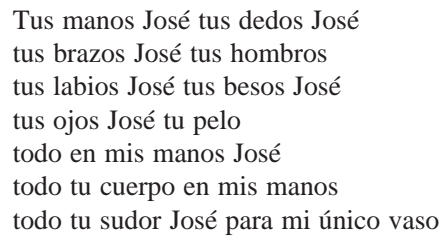

\footnotetext{
${ }^{19}$ La epidemia del SIDA es uno de los temas principales de la generación de poetas puertorriqueños y latinos residentes, en su mayoría, en Estados Unidos. Entre ellos se destacan Moisés Agosto, Joey Pons, Nemir Matos, Francisco X. Alarcón, entre otros. Sobre la epidemia del SIDA en Puerto Rico ver el volumen "Puerto Ricans and AIDS it’s Time to Act!" Centro de Estudios Puertorriqueños Bulletin; y la antología poética POESída Antología de poesía del SIDA escrita en Estados Unidos, Hispanoamérica y España. An Anthology of AIDS Poetry from the United States, Latin America and Spain (Carlos Rodríguez Matos, editor).
} 


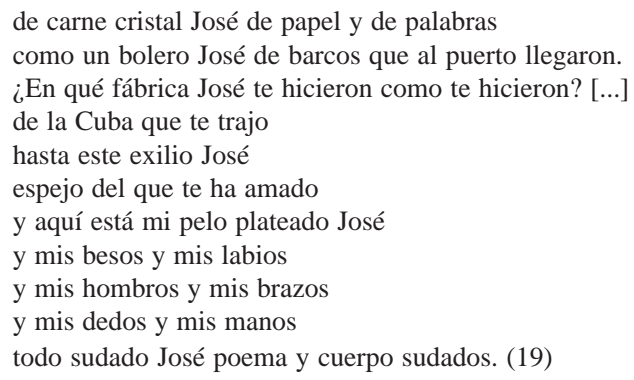

Aquí, el cuerpo del amado se fragmenta para proveerle cuerpo al texto poético: "la carne de cristal José de papel y palabras”. Este cuerpo de la escritura pertenece a un "cuerpo del exilio”, del viajante que no posee una relación directa con un entorno geográfico. Y desde ahí se representa una relación creativa y erótica entre los dos cuerpos: el deseo por el amado produce el poema y el poema produce el cuerpo del amado. Por consiguiente, es sólo desde esta fragmentación del cuerpo del amado y desde un deseo mediado por la seducción del poema que se produce "el poema sudado" y “el cuerpo de papel y palabras".

En el poema 6 se reelabora el tema de la ausencia del amante y aunque esta ausencia se utiliza, como ya señalé anteriormente, como motivo creador de poesía, el cuerpo del amado se desvanece, mientras que, el motivo de la espera y la soledad busca abolir los recuerdos y fijarlos a un espacio determinado:

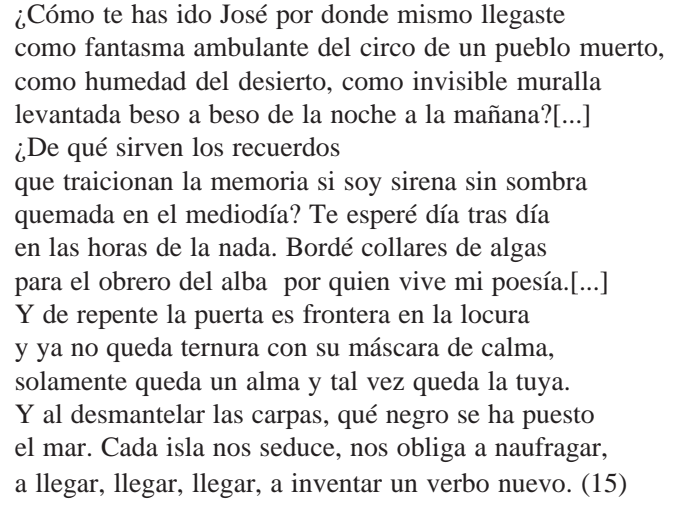

En este poema, la composición misma de los versos alejandrinos con rima concatenada elabora el texto seductor de la poesía del cortejo amoroso y la espera por el amado. Estos versos, que recuerdan la búsqueda por el amado del “Cántico espiritual” de San Juan de la Cruz, reproducen ese mismo espacio místico y cromático de un viaje desde adentro hacia afuera. La conjunción de imágenes del circo del pueblo muerto, la muralla en ruinas remiten a este “afuera” textual y antirreferencial. Es aquí cuando la memoria se convierte en un juego 
de temporalidades y la puerta hacia "la locura” se sitúa en un espacio íntimo: el alma del amado. Por consiguiente, el "desmantelar carpas” alude a un texto físico, el imaginario circense y carnavalesco del espacio que se añora (la Isla) que pasa a ser un significante múltiple. Cada isla multiplicada como espacio de ausencia produce un doble discurso del naufragio y la vuelta. Nótese que el amante es "un alma” posible que ha perdido sus cualidades corporales, su relación con un espacio definido y actúa como significante de la búsqueda, mientras que el sujeto poético se construye desde una heterogeneidad metafórica: ("sirena sin sombras", "sombras") hasta desvanecerse. Por lo tanto, la memoria de un cuerpo ausente produce el poema, en donde la identidad se abre a la multiplicidad de islas y el "verbo nuevo" remite a un proceso continuo de creación.

Mas, sin embargo, es en el poema 29, uno de los más logrados del texto, que se reformula una conjunción coherente del discurso del deseo, la ausencia del amado y el tránsito lográndose un texto metapoético. Este, como el soneto de Lope de Vega titulado "Un soneto me manda a hacer Violante”, reproduce el alarde y la seducción de la creación para abolir una memoria del pasado y concentrarse en el momento mismo de la creación:

Estás enamorado.

Caminas por la calle del exilio

persiguiendo el recuerdo de una niebla[...]

No llega ni llegará el amado

El nunca fue pájaro en mano

sino cuerpo tembloroso en tu camino.

Estás perdido[...]

Tienes catorce años, estás en Puerto

Rico y te has enamorado de un ángel.

Escribes cuentos de cuerpos con alas

escondidos en las arrugas de un lecho[...]

Juras que no amarás jamás,

tu escritura será la salvación o el castigo[...]

Cambia la luz del semáforo y cruzas.

En New York se avecina una noche calurosa de otoño[...]

Entras a la bodega pero el no está[...]

No han hecho cita. A lo mejor vendrá.

Estás hecho de tiempo.

Tienes miedo al amor

o a la pasión que amenaza

tu pasión por la escritura[...]

Te sientes naufragado.

la noche suda negra sobre la brea.

Piensas que un delirio de drogas

sería la respuesta para la soledad.[...]

¿Cúal de los que amaste regresó

para abrazarte de la misma manera?

¿Qué se queda? Un charco en la acera[...]

No dudes que el te amó. No mires atrás.

A lo mejor te ama desde su laberinto[...]

Se habrán reconocido desde lejos 
y se saben espejos de los que no se tocan[...]

El presente es perfecto. Es todo lo que tienes.

Has descubierto el puente que da sentido al tiempo

que pensabas perdido. La prueba es el poema

que has escrito. (39-41)

Este poema autorreflexivo es un "poema conjetural” de "ajuste de cuentas”, en el que el deseo por el otro se internaliza y provoca una reflexión de la vida y la escritura. La persona poética ya no aparece disfrazada en un juego continuo de personas poéticas sino que se recupera en un "tú" donde la "calle del exilio" es el laberinto textual de lo vivido como poema mismo. El gesto de la escritura como presencia y prueba de lo presente, recupera un espacio intermedio entre yo y el otro como juegos de poder en el sujeto colonial. También propone un espacio medio entre el amante y el amado, el deseo por el otro y la ausencia desesperante, el cuerpo del amado y el espacio vital, la escritura y el poema. Por lo tanto, los continuos desplazamientos provocados por el exilio representados a su vez por el cuerpo del amado ausente, se reformulan desde el espacio indeterminado de la escritura y la creación poética.

Este espacio es el que se reproduce en el poema "Insomnio", donde la enfermedad recrea otro tránsito entre la vida y la muerte. En esta lectura la muerte se incorpora como motivo de creación, y se refiere a la muerte simbólica del sujeto poético:

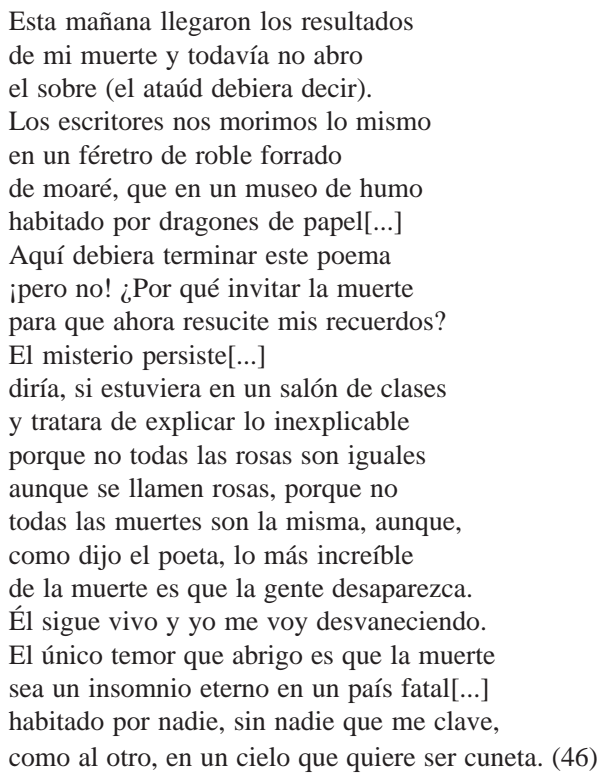

Aquí, el tema de la muerte se propone como texto contiguo al poema. El ataúd se convierte en el papel y a la misma vez la vida pasa a ser poesía. Por otro lado, el cuerpo del 
amado se encuentra en un afuera mientras se establece un juego de distancias entre la otredad escrita y la ficcional o literaria. Por consiguiente, “el otro" y "El” reproducen una identidad de la escritura, mientras que puede asociarse a una entidad metafísica fuera del cuerpo. Sin embargo, el acto sexual "sin que nadie me clave” establece un patrón discursivo que actúa como un lenguaje propio. La metáfora del exilio como tránsito se sustituye por la del tránsito entre la vida y la muerte, mientras que, el cuerpo del deseo se desvanece reformulando el acto como lenguaje, la textualidad misma del poema vital. De ahí que lo único que se recupere en el instante de creación poética donde se abole la identidad de un amado y se propone la muerte del "yo poético" sea el acto sucesivo de "clavar” el papel como cuerpo e inscribir la escritura. Es así como texto poético, corporalidad y deseo se transforman aquí para crear su propia "grafía” en la escritura.

En conclusión, en Invitación al polvo, el discurso del deseo se propone desde un espacio que va más allá del amante y del espacio corporal — geográfico/ cultural—que lo define. Este distanciamiento de categorías produce un desplazamiento de la subjetividad lírica de la voz poética, que termina convirtiéndose desde la ficción en un exiliado del mundo, un viajero perpetuo. Sin embargo, estas categorías de exilio que no remiten ya a un espacio definido - ya el balcón de la Norzagaray se "desmonta”- y reformulan un discurso donde la subjetividad de lo latinoamericano o lo caribeño se rescata. Por consiguiente, "el exilio” y el tránsito remiten al intelectual latinoamericano, y una retórica del deseo que intenta traducir un espacio propio mientras "se traga” unos códigos culturales provenientes de un "afuera” que termina confundiéndose con "lo propio". Es, desde este punto de vista, que se recupera "El fiel y frágil Borges” (69) y las quimeras del tiempo como entidad femenina como cuerpo deseante/deseado en la representación. Por lo tanto, el intento de creación en Invitación al polvo parte de un discurso del deseo por el otro, como entidad en un afuera para crear un texto poético que traduce las relaciones complejas con un espacio que ya no corresponde a categorías geográficas o lingüísticas, sino a la ficción. Es así como desplazarse en un continuo tránsito es apropiarse ficcionalmente de un espacio, desearlo y poseerlo. Mientras que el deseo por el otro propicia la búsqueda creativa creando y asimilando el cuerpo erótico del texto poético.

\section{Conclusión: PoÉticas móviles}

¿Encontraría a la Maga? Tantas veces me había bastado asomarme, viniendo por la rue de Seine, al arco que da al Quai de Conti, y apenas la luz de ceniza y olivo que flota sobre el río me dejaba distinguir las formas, ya su silueta delgada se inscribía en el Pont des Arts [...] Y era tan natural cruzar la calle, subir los peldaños del puente, entrar en su delgada cintura y acercarme a la Maga que sonreía sin sorpresa, convencida como yo de que un encuentro casual era lo menos casual en nuestras vidas[...]

—Julio Cortázar, Rayuela

Entonces, ¿qué texto escapa a partir de su motivación creadora a este discurso del deseo? El deseo por el otro, el texto de la espera por el amante, equivale a construir un "kibbutz del deseo" textual en donde el exilio se construye como ficción y las temporalidades confluyen y abolen el espacio geográfico. Por consiguiente, los amantes exilados en la 
poesía de Ramos Otero se permiten construir un texto amoroso en común en donde las mismas historias del exilio se traducen continuamente desplazando los espacios. Puede afirmarse que el tránsito y el exilio reproducen desde sus desplazamientos “otra” configuración del deseo y el texto corporal sobre el amante. Esta es la del texto escrito confluyendo con el cuerpo del deseo para producir el espacio de la calle, la ciudad y el paseante como ficción. Para De Certeau, el paseante que camina la ciudad y se mezcla con sus habitantes reproduce una ficción, un texto propio de posesión erótica: "an Icarus flying above these waters, he can ignore the devices of Daedalus in mobile and endless labyrinths far below. His elevations transfigures him into a vouyeur[...] It allows one to read it, to be a solar Eye, looking down like a God” (152).

En el Libro de la muerte, el “cruceo” representa esta apropiación de un nuevo espacio donde el cuerpo-fetiche del hombre de cuero encarna el "objeto de placer” como momento de concientización agencial. Esta "toma de conciencia” en el bar nocturno de Christopher Street reclama el deseo homosexual como agente creador. Por consiguiente, el "cruceo" y el cuerpo como metáfora reproduce la entrada a un discurso del poder en donde se alegoriza el "cruceo" de identidades culturales (emigrantes) y políticas (sujeto colonial). Aunque esta concientización produce un instante “epifánico” de creación textual, es a partir de la máscara travesti que se problematiza la "máscara del exilio” del sujeto colonial. Ésta desde la alegoría del desplazamiento y de la espera, se transforma en Penélope, Tsugichumo, o Maba, diluyendo el cuerpo y produciendo un texto de la añoranza en donde la Norzagaray se reproduce en un "afuera” que se observa desde la subjetividad enmascarada: Tsugichumo observa desde el balcón de la casa de papel el paso de su entierro, mientras Penélope teje la red de la espera cerca del mar amurallado de San Juan. Este espacio se reproduce a su vez con trazos carnavalescos de circo, los cuales construyen un texto circular desde sus metáforas y cambiante al mismo tiempo desde la máscara poética. Es así como la máscara se sitúa entre los dos espacios geográficos y metaforiza el exilio, produciendo las heterogeneidades de la subjetividad colonial. Sin embargo, aunque estas heterogeneidades se representan parecen problematizarse a medida que el cuerpo del deseo se desvanece. Puede afirmarse, entonces, que El libro de la muerte reformula un instante de concientización de la voz poética desde su sexualidad para con su entorno y que a partir de la máscara poética es que se problematizan estas relaciones. Por consiguiente, al recuperarse un discurso sobre la espera del amante, el cuerpo ausente reproduce el tránsito continuo y la ausencia del exilado, que “desvanece” el cuerpo del amante y lo ausenta para reinscribirse en su propia ausencia.

Es, entonces, a partir de esta serie de ausencias que Invitación al polvo reclama una vuelta al proceso de escritura en sí mismo, como texto erótico y metapoético. La presencia de José, el amante cubano, como cuerpo fragmentado y representativo del Caribe produce a su vez una meditación sobre lo latinoamericano. Por un lado, el texto se abre a una perspectiva más amplia, proponiendo el exilio individual como una metáfora amplia del exilio latinoamericano. Por otro, este texto reelabora la teatralidad de la máscara para proponerla desde un espacio más fluido, en donde, todos los registros cultos (Siglo de Oro) o populares (el bolero) se transforman para encarnar la creación poética. Aunque el cuerpo se encuentra presente, desde las metáforas de la enfermedad, el deterioro físico y el viaje 
todas se recuperan desde la escritura. Por ejemplo, el SIDA de "Nobleza de sangre" (6263) parte de la autobiografía y se sitúa en los estereotipos creados por los medios de comunicación, la relación entre los dos amantes es un bolero y el deterioro físico se lee a partir de "La rosa" de Sor Juana. Por consiguiente, los códigos de representación se problematizan produciendo un lenguaje que remite a la poesía misma. Y aunque el cuerpo del amado continúa produciendo el texto de la búsqueda, el cuerpo se desvanece para reformularse como ficción.

Es así como se se retoma la metáfora del viajero perpetuo y el exilio como espacio de hibridez y traducción cultural. A partir de la desaparición del cuerpo del amante como referente, el tránsito va produciendo la posibilidad de la escritura. La escritura "media”, sin embargo, en lugares de sueño y de ausencia. Por lo tanto, el exilio reformula el deseo por el otro, como cuerpo ausente, como espacio, y lo problematiza haciendo posible la creación de textos “híbridos” cultural y espacialmente. Esta fragmentación del sujeto poético revela las contradicciones de una identidad colonial y crea a su vez las estrategias representativas del deseo homosexual. El amante reproduce en el amado su "mismidad" y su diferencia en lo sexual y en lo político. Para Bhabha este proceso de "mimicry” en el sujeto colonial, produce un texto incompleto donde el significante predomina y en donde categorías como el adentro/afuera se transforman. En ese sentido, la ausencia del amante puede leerse desde esas ambigüedades del sujeto colonial. A partir de estas reformulaciones de la "otredad" —adentro y afuera— se crea un sujeto poético múltiple y móvil. Estas "poéticas móviles” se erigen como un cruce de lenguajes creativos y erotizados. Mas sin embargo, esta posesión es transitoria, y desde su transitoriedad es que construye las pulsiones del deseo. En estas categorías de textualidad deseante, "traductora” y transitoria el desplazamiento entre la Norzagaray y Christopher Street va inscribiendo y borrando las posibles fijaciones a un espacio determinado y al deseo inscrito en un rostro.

De ahí que el deseo cree los significantes de esta poética transeúnte. Aquí, la corporeidad del poema es el único signo posible, mientras que el amante/cuerpo como referente y nombre se desvanece. De ese modo, se va construyendo el relato amoroso. Así, el amante es un rostro y puede no ser ninguno, el espacio que se añora puede remitir a ambas calles, a todas, o a ninguna. Es, entonces, cuando el poema produce, a partir del exilio, su epifanía erótica en ese vacío de ausencias y el predominio de la palabra, en ese amantecuerpo que no llega y el recuerdo de una calle solitaria.

\section{BiBLIOGRAFÍA}

“Puerto Ricans and AIDS it’s Time to Act!” Centro de Estudios Puertorriqueños Bulletin. IV/1-2 (1994).

Abelove Henry, Michèle A. Barale y David M. Halperin. The Lesbian and Gay Studies Reader. Nueva York : Routledge, 1993.

Almaguer, Tomás. “Chicano Men: A Cartography of Homosexual Identity and Behavior”. The Lesbian and Gay Studies Reader. Nueva York: Routledge, 1993. 255-73.

Alonso, Ana María y María T. Koreck. "Silences: "Hispanics”, AIDS, and Sexual Practices”. The Lesbian and Gay Studies Reader. Nueva York: Routledge, 1993. 11026. 
Arroyo, Jossianna. "Manuel Ramos Otero: las narrativas del cuerpo más allá de Insularismo”. Revista de Estudios Hispánicos xxi (1994): 303-24.

Barthes, Roland. Fragmentos de un discurso amoroso. México: Siglo xxi, 1989.

Bersani, Leo. “Is the Rectum a Grave?” October. Cambridge, 43. (1987): 197-222.

Bhabha K., Homi. “The Commitment to Theory”. New Formations 5 (Summer 1988): 522.

"DissemiNation: time, narrative and the margins of the modern nation". Nation and Narration. Homi K. Bhabha, ed. Londres: Routledge, 1991. 291-322.

"Of mimicry and man: The ambivalence of colonial discourse". The Location of Culture. Londres: Routledge, 1994. 85-92.

Butler, Judith. Gender Trouble. Feminism and the Subversion of Identity. Nueva York: Routledge, 1990.

Braunstein, Néstor A. "Las pulsiones y la muerte (Collage)". La reflexión de los conceptos de Freud en la obra de Lacan. México: Siglo xxi, 1983. 11-80.

Cruz Malavé, Arnaldo. "Para virar al macho: la autobiografía como subversión en la cuentística de Ramos Otero”. Revista Iberoamericana LXIX/162-163 (enero-junio 1993): 239-63.

De Certeau, Michel. "Walking in the City". The Cultural Studies Reader. Londres: Routledge, 1993. 151-60.

Díaz Quiñones. "La memoria rota”. La memoria rota. Ensayo sobre cultura y política. Río Piedras: Huracán, 1993. 67-86.

Edelman, Lee. "Tearooms and Sympathy, or the Epistemology of the Water Closet". Nationalisms and Sexualities. Parker, Russo, Sommer y Yaeger, eds. Londres/Nueva York: Routledge, 1992.

Evans, David T. Sexual Citizenship. The Material Construction of Sexualities. Londres: Routledge, 1993.

Fanon, Frantz. The Wretched of the Earth. Constance Farrington, trad. Nueva York: Grove Press, 1963.

Flores, Juan. "National Culture and Migration: Perspectives for the Puerto Rican Working Class" (with Ricardo Campos) Divided Borders Essays on Puerto Rican Identity. Houston: Arte Público Press, 1993. 111-41.

“The Insular Vision: Pedreira and the Puerto Rican Misère”. Divided Borders Essays on Puerto Rican Identity. Houston: Arte Público Press, 1993. 13-60.

y George Yúdice. "Living Borders/ Buscando América: Languages of Latino Self Formation”. Divided Borders Essays on Puerto Rican Identity. Houston: Arte Público Press, 1993 199-224.

Foucault, Michel. Discipline and Punish. The Birth of the Prison. Alan Sheridan, trad. Nueva York: Vintage Books, 1979.

The History of Sexuality. The Use of Pleasure. Robert Hurely, trad. Nueva York: Vintage Books, 1990.

García Canclini, Néstor. Culturas híbridas. Estrategias para entrar y salir de la modernidad. Buenos Aires: Sudamericana, 1992.

Gelpí, Juan G. “La escritura transeúnte de Manuel Ramos Otero”. Literatura y paternalismo en Puerto Rico. Río Piedras: Ed. U.P.R., 1993. 137-53. 
Memmi, Albert. The Colonizer and the Colonized. Boston: Beacon Press,1991.

Molloy, Silvia. “The Politics of Posing”. Hispanisms and Homosexualities. Sylvia Molloy y Robert Mc Kee Irwin, eds. Durham: Duke University Press, 1997. 141-60.

Monsiváis, Carlos. Escenas de pudor y liviandad. México: Grijalbo, 1981.

Montero, Oscar. “The Signifying Queen: Critical Notes from a Latino Queer”. Hispanisms and Homosexualities. Sylvia Molloy y Robert Mc Kee Irwin, eds. Durham: Duke University Press, 1997. 161-74.

Negrón-Muntaner Frances y Ramón Grosfoguel (Eds.). "Beyond Nationalist and Colonialist Discourses: The Jaiba Politics of the Puerto Rican Ethno-Nation”. Puerto Rican Jam: Essays on Culture and Politics. Minneapolis: University of Minnesota Press, 1997. $1-38$.

Parker Andrew, Mary Russo, Doris Sommer y Patricia Yaeger (Eds.). “Introduction”. Nationalisms and Sexualities. Nueva York: Routledge, 1992. 1-14.

Parker, Richard. Beneath the Equator: Cultures of Desire, Male Homosexuality and Emerging Gay Communities in Brazil. Nueva York: Routledge, 1999.

Patton, Cindy. "From Nation to Family: Containing African AIDS". The Lesbian and Gay Studies Reader. Nueva York : Routledge, 1993. 127-38.

Perlongher, Néstor. “Poesía y éxtasis”. Prosa plebeya. Ensayos 1980-1992. Selección y prólogo de Christian Ferrer y Osvaldo Baigorria. Buenos Aires: Colihue, 1997. 14954.

Ramos Otero, Manuel. Cuentos de buena tinta. San Juan: Instituto de Cultura Puertorriqueña, 1992. Invitación al polvo. España: Ed.Plaza Mayor, 1991.

Homenaje a Manuel Ramos Otero 1948-1990. Río Piedras. Universidad de Puerto Rico, ocho de marzo de 1991.

Página en blanco y stacatto. España: Ed. Playor, 1987.

El libro de la muerte. San Juan: Ed. Cultural \& Waterfront Press, 1985.

“De la colonización a la culonización”. Cupey 8 (1991): 63-79.

Ramírez, Rafael L. Dime capitán: reflexiones sobre la masculinidad. Río Piedras: Huracán, 1993.

Ríos, Rubén. “Caribbean Dislocations: Arenas and Ramos Otero in New York”. Hispanisms and Homosexualities. Sylvia Molloy y Robert Mc Kee Irwin, eds. Durham: Duke University Press, 1997. 101-22.

Rodríguez Matos, Carlos E. (Ed.). POESída Antología de poesía del SIDA escrita en Estados Unidos, Hispanoamérica y España. An Anthology of AIDS Poetry from the United States, Latin America and Spain. Nueva York: Ollantay Press, 1995.

Rubin, Gayle S. "Thinking Sex: Notes for a Radical Theory of the Politics of Sexuality”. The Lesbian and Gay Studies Reader. Abelove, Barale, Halperin, eds. Nueva York/ Londres: Routledge, 1993. 3-44.

Said, Edward. Orientalism. Nueva York: Random House, 1979.

Santos, Mayra. "La venganza de los circuitos cerrados”. Musturbana 1/1 (Río Piedras, abril 1994): 3-6.

Sarduy, Severo. Escrito sobre un cuerpo. Ensayos de crítica. Buenos Aires: Sudamericana, 1969. 
Sarup, Madan. Jacques Lacan.Toronto: University of Toronto Press, 1992.

Seed, Patricia. “More Colonial and Postcolonial Discorses”. Latin American Review 28/ 3 (1993): 146-52.

Vega, José Luis. “La poesía de Manuel Ramos Otero”. Homenaje a Manuel Ramos Otero.

Río Piedras: Universidad de Puerto Rico, 1991. 16-24.

Waley, Arthur. The Nö Plays of Japan. Nueva York: Grove Press, 1957. 15-59. 